\title{
Degradation Kinetics and Mechanical Studies of Intumescent Coated Cotton Fabric
}

\author{
Satish Kumar ${ }^{1}$, Sohan Lal ${ }^{2}$ and Sanjiv Arora ${ }^{2, *}$ \\ ${ }^{1}$ Department of Chemistry, University College, Kurukshetra University, Kurukshetra-136 119, India \\ ${ }^{2}$ Department of Chemistry, Kurukshetra University, Kurukshetra-136 119, India
}

\begin{abstract}
In the present study, cotton fabric were prepared via coating with intumescent formulations of ammonium polyphosphate (APP), guanidine nitrate, penta erythritol (PER) and metal salts at different loading levels via 'Pad-dry cure' method. Thermal degradation behavior of prepared cotton derivatives was investigated by thermogravimetry (TG) and differential thermal analysis (DTA) from ambient temperature to $700{ }^{\circ} \mathrm{C}$. Dynamic TG analysis was used to study the thermal degradation behavior of samples at four different heating rates of $2,5,10$ and $20^{\circ} \mathrm{C} \mathrm{min}-1$ in air atmosphere. The treated cotton fabric decomposes at lower temperatures and produces higher amount of char yields. The degradation activation energy was calculated using Friedman, modified Coats-Redfern and Ozawa-Flynn-Wall (O-F-W) isoconversional model free methods. Tensile properties of coated fabric were found to be reduced with increase in loading of intumescent formulation but there was an abrupt increase in sample coated with intumescent and silica. With the insertion of iron $(\mathrm{Fe})$ metal ion along with intumescent reduces the fabric strength due to formation of metal complexes with cotton cellulose which decreases the crosslinking. The maximum flame ratardancy of CF 12APP-Si among all cotton derivatives is suggested as the flame retardancy directly proportional to char yield $\left(22 \%\right.$ at $\left.650{ }^{\circ} \mathrm{C}\right)$ that is highest and inversely proportional to MMLR value $\left(8.3 \% \mathrm{~min}^{-1}\right)$, that is least among all samples. Based on thermal and kinetic studies, the optimum concentration of flame retardant is worked out.
\end{abstract}

Keywords: Model free kinetics, Thermal Analysis, CRA, Pad-Dry Cure, MMLR.

\section{INTRODUCTION}

Fire is constructively used in many applications in industry and domestic level. There is no estimate of the extent of personal and industrial injuries and destroys property due to the ignition of textiles, but magnitude is quite high. When cellulose catches fire it undergoes thermal degradation [1], forming combustible volatile compounds which further involved in the propagation of fire. These volatile compounds also create environment pollution. So to overcome these problems of cellulosic materials, a number of organizations along researchers [2-5] have been active in search for better flame retardants that would be effective and durability of fabric.

Several treatments of phosphates, sulphates, halides and metal deposits on cotton or cellulose have been made to make them flame retardant $[6,7]$. These treatments require, more time at elevated temperatures (risk of degradation of cellulose), a lot of exercise, carsoceneous chemical, hazardous chemicals, heterocyclic compounds as catalyst and problem of disposal of waste material [8]. Even with these chemical, there is decrease in the tensile strength of cotton fabric. The main concern of researchers these days is the intumescent coating $[9,10]$ for enhancing

*Address correspondence to this author at the Department of Chemistry, Kurukshetra University, Kurukshetra-136 119, India; Tel: +91-9416566014; Fax: +91-1744 238049; E-mail: sanjivkuk@yahoo.co.in flame retardancy of polymers/cotton. Intumescent formulations have been applied for various plastic materials [11] from many decades. In the present study we are using intumescent coating on series of fabrics to make these flame retardant. An intumescent is a mixture of inorganic acids like phosphoric acid or phosphates (dehydrating agent), a polyhydric material rich in carbon (char forming agent) and a blowing or spumific agent (nitrogen rich) [12]. The main function of intumescent coating is to shield the underlying material from the fire.

In the present research, we investigate the kinetics of thermal degradation of CF and intumescent coated fabrics, in several proportions along with metal composites and silica powder at multiple heating rates of $2,5,10$ and $20{ }^{\circ} \mathrm{C} \mathrm{min}{ }^{-1}$ in air from ambient temperature to $700{ }^{\circ} \mathrm{C}$. To calculate kinetic parameters for thermal degradation of above samples, Model free kinetic [13] methods i.e. Friedman [14], Coats-Redfern [15] modified and Ozawa-Flynn-Wall [16] methods at various degree of conversions $(\alpha)$ were applied.

\section{EXPERIMENTAL}

\subsection{Materials}

For intumescent formulation ammonium polyphosphate (APP), guanidine nitrate and pentaerythritol (PER) were purchased from National Chemicals, Gujarat (India). Cotton fabric (2mm suiti) 
Table 1: Formulation of All Fabrics in Specific Proportions

\begin{tabular}{|c|c|c|c|c|c|}
\hline \multirow[t]{2}{*}{ Samples } & \multicolumn{3}{|c|}{ Intumescent } & \multicolumn{2}{|c|}{ Metals } \\
\hline & APP (g) & Guanidine (g) & PER (g) & 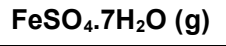 & Silica-powder (g) \\
\hline $\mathrm{CF}$ & - & - & - & - & - \\
\hline CF 6APP & 6 & 2 & 2 & - & - \\
\hline CF 9APP & 9 & 3 & 3 & - & - \\
\hline CF 12APP & 12 & 4 & 4 & - & - \\
\hline CF 12APP-Fe & 12 & 4 & 4 & 1 & - \\
\hline CF 12APP-Si & 12 & 4 & 4 & - & 1 \\
\hline CF 15APP & 15 & 5 & 5 & - & - \\
\hline
\end{tabular}

brought from Mafat Lal Co. Mumbai (India). Other chemicals of analytical grade used are ferrous sulphate heptahydrate $\left(\mathrm{FeSO}_{4} .7 \mathrm{H}_{2} \mathrm{O}\right)$, Silica powder and water based Acrylic resin.

\subsection{Sample Preparation}

APP (as acid source), PER (as charing source) and guanidine (swelling agent) was mixed in ratio of $3: 1: 1$ to make intumescent flame retardant system. $10 \mathrm{~g}$ of intumescent formulation and $12 \mathrm{~g}$ (acrylic was 30\% w/w of Cotton fabric) acrylic mixed with a little of water in pastel- mortar manually then pasted on one side of cotton fabric of $40 \mathrm{~g}(40 \mathrm{~cm} \times 40 \mathrm{~cm})$ by small paint brush represented as CF 6APP. The sample was dried in air for few minutes and then cured in oven at $125^{\circ} \mathrm{C}$ for 10 minutes. Similarly other samples are prepared with formulation of intumescent and metal salts as described in Table 1.

\subsection{Tensile Strength and Crease Recovery Angle}

For measurement of tensile strength of fabric, the samples of $25 \mathrm{~mm} \times 120 \mathrm{~mm}$ dimensions were used. Crease recovery angle [17] (bending hysteresis) of samples was measured using dimensions of $120 \mathrm{~mm} \mathrm{x}$ $120 \mathrm{~mm}$.For this a load of $2 \mathrm{~kg}$ exerted on one-fold of fabric sample for 1 minute and then the angle measured.

\subsection{Thermal Analysis}

Thermal degradation of $\mathrm{CF}$ and treated fabrics were carried out by thermogravimetry (TG) and Differential thermal analysis (DTA) simultaneously in TG/DTA Perkin Elmer instrument. Small amount (about $10 \mathrm{mg}$ ) of dried samples in ceramic sample pans were analyzed so that there would be negligible temperature gradients within the sample over the complete analysis from ambient temperature to $700{ }^{\circ} \mathrm{C}$ at multiple heating rates of $2,5,10 \& 20^{\circ} \mathrm{C} \mathrm{min}{ }^{-1}$ in air flow of $40 \mathrm{~mL} \mathrm{~min}^{-1}$.

\section{RESULT AND DISCUSSION}

\subsection{Crease Recovery Angle (CRA) and Tensile Strength}

It was found the crease recovery angle is $95^{\circ}$ for cotton fabric in weft direction. Crease recovery angle of intumescent coated cotton fabrics was decreased up to $88-83^{\circ}$ in case of CF $12 \mathrm{APP}-\mathrm{Fe}$. There was very less effect on crease recovery angle of CF 12APP-Si, which was slightly less than pure cotton fabric (Figure 1). It has been reported by various researchers $[18,19]$ that the CRA increases with increasing curing temperature, Ramchanderan et al. [20] reported the value of CRA for untreated CF as 88.

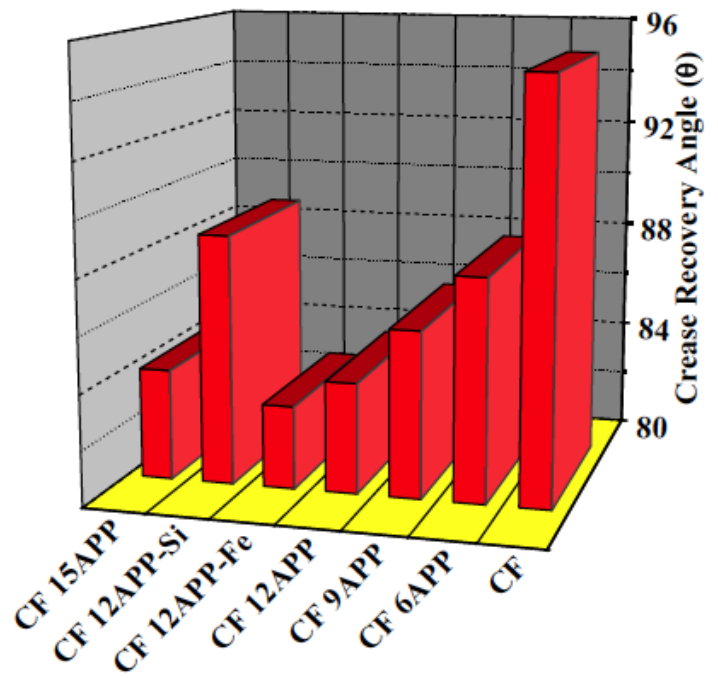

Figure 1: Crease Recovery angle of Cotton Fabric and its derivatives.

Crosslinking cotton cellulose reduces tensile strength of the treated cotton fabric [21]. Yang et al. [22] studied that the tensile strength loss was the 


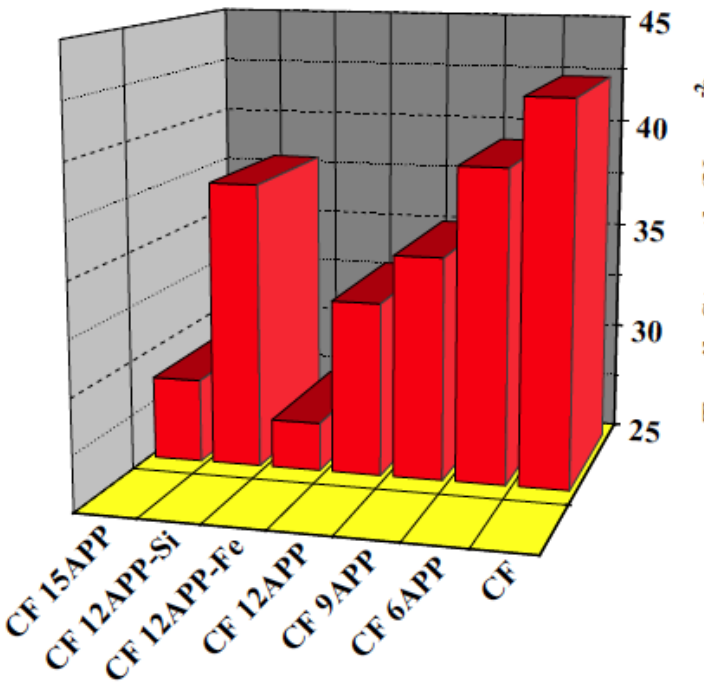

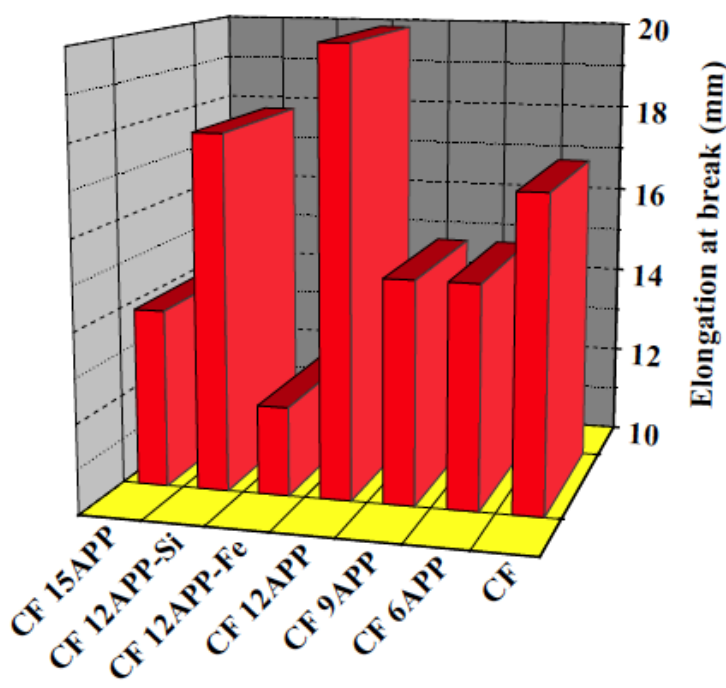

b

Figure 2: a: Tensile strength of cotton fabric and its derivatives.

b: Elongation at break for cotton fabric and its derivatives.

combined effects of acid degeneration and crosslinking of cellulose. Fabric strength loss caused by acid degeneration is irreversible but fabric strength loss due to crosslinking is reversible [23]. Therefore fabric strength depends upon curing temperature and time. Cotton fabric treated with phosphates at high curing temperature for longer time period means more acid degeneration. Ultimately more acid degeneration and fabric strength loss is large. No doubt the tensile strength of fabric must be decreased, by adding phosphates in fabric. But in the treatment of intumescent coating by pad-dry curing $\left(125{ }^{\circ} \mathrm{C}\right.$ for 10 minutes) of cotton fabric, tensile strength of substrate fabric is less affected from other type of chemical treatments, because curing period is only for 10-15 minutes whereas chemical treatment of phosphates with cotton were at elevated temperatures for $48-72$ hrs. Tensile strength of CF 12APP-Si was $42 \mathrm{~N} \cdot \mathrm{mm}^{-2}$ elongations at break of $18 \mathrm{~mm}$ which is nearly equal to CF caused by crosslinking of cotton cellulose with silicates present in silica, which increases the fabric strength or intermolecular forces of bonding increases leads to enhance tensile strength [24], shown in Figures $\mathbf{2 a}$ and $\mathbf{b}$. Waichiro et al. [25] reported that the tensile strength of $\mathrm{CF}$ is remarkably decreased with decrease in degree of polymerization. Tensile strength of CF decreases due to intervening of phosphates into the matrix of control fabric, causes decrease in degree of polymerization. It may be concluded that the tensile strength decreases with increasing phosphate concentration followed by metals. Here the least value of tensile strength for CF 12APP-Fe was found.

\subsection{Thermal Analysis}

The effect of the heating rate on TG curves (Figure 3) may be observed, that on increasing the heating rate, curves are shifted to the right, i.e. the more mass losses at increasing temperatures [26]. This behavior has been described by several researchers and can be explained using different arguments. Possibility of poor heat transmission to the sample in the TG/DTA oven may cause increasing differences with increasing heating rate between the nominal and real temperature of the sample. It could also be due to different rates of heat absorption/spent of the reaction at different heating rate.

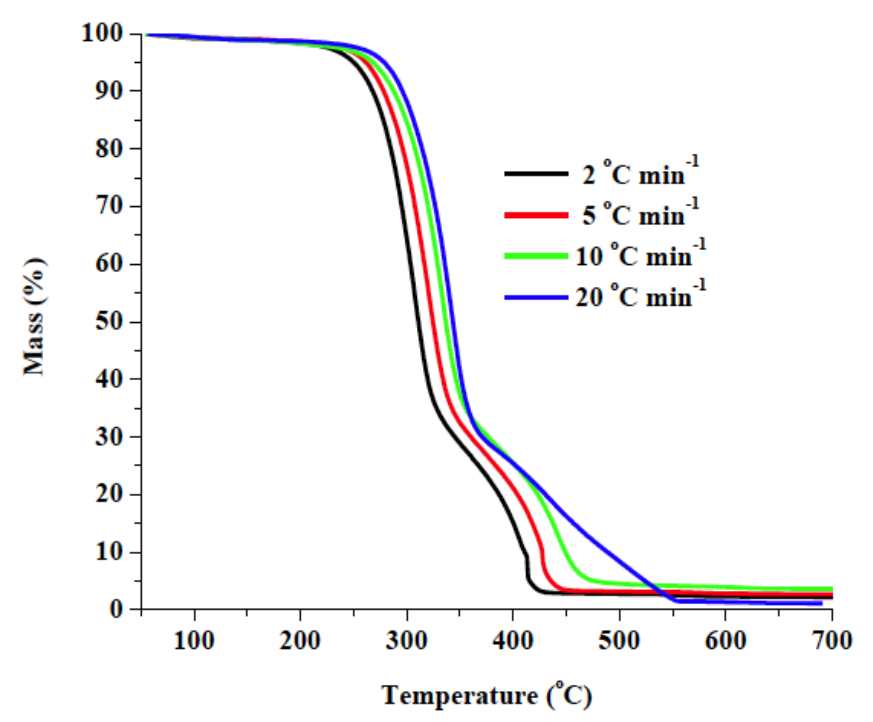

Figure 3: TG curves for $\mathrm{CF}$ at different heating rates of 2, 5 , 10 and $20^{\circ} \mathrm{C} \mathrm{min}^{-1}$ in air. 


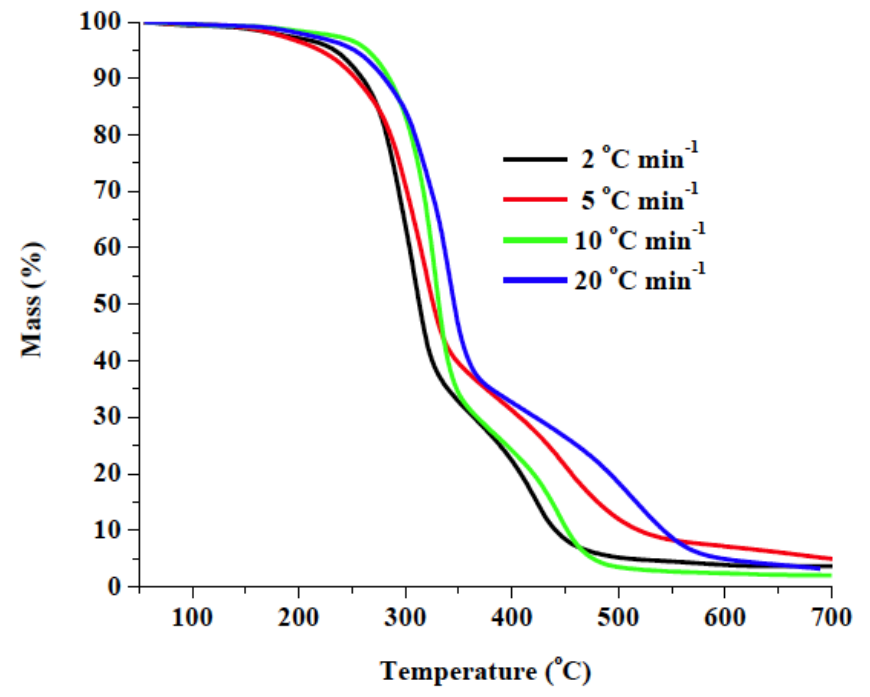

Figure 4: TG curves for CF 6APP at different heating rates of $2,5,10$ and $20^{\circ} \mathrm{C} \min ^{-1}$ in air.

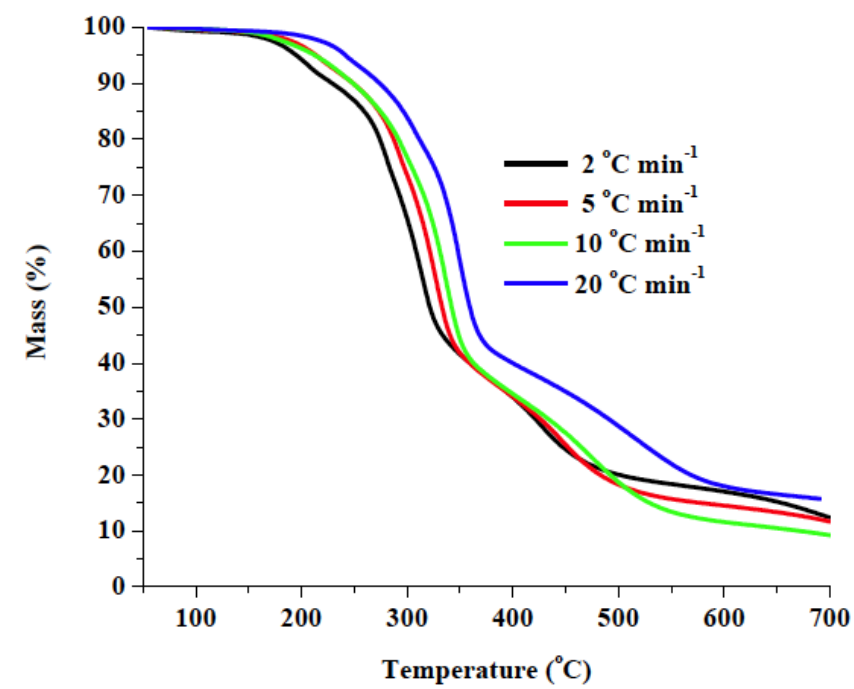

Figure 5: TG curves for CF 9APP at different heating rates of 2, 5, 10 and $20^{\circ} \mathrm{C} \min ^{-1}$ in air.

In the TG curves of all samples at multiple heating rates (Figures 3-9), the degradation starts at lower temperature for heating rate of $2{ }^{\circ} \mathrm{C}$ then 5,10 and 20 ${ }^{\circ} \mathrm{C}$ in sequence. TG curves of all samples at a heating rate of $10^{\circ} \mathrm{C} \mathrm{min}^{-1}$ in air are shown in Figure 10a. The data observed from TG and DTG curves of samples at heating rate of $10{ }^{\circ} \mathrm{C} \mathrm{min}-1$ are reported in Table 2. The onset degradation temperature (TO) of control $\mathrm{CF}$ is $\sim 281{ }^{\circ} \mathrm{C}$ and for $\mathrm{CF} 12 \mathrm{APP}-\mathrm{Si}$ is $\sim 318{ }^{\circ} \mathrm{C}$. This measurable increase is due to presence of Silica (clay) that increases the thermal stability of intumescent coated fabric. Therefore it may be concluded that the insertion of metal ion $(\mathrm{Fe})$ or $\mathrm{Si}$ are increasing the thermal stability of intumescent coated cotton fabric. The mass loss $\left(\mathrm{ML}_{\circ}\right)$ referrers to onset degradation temperature for sample exist in range of $5-28 \%$ that causes due to dehydration and decomposition process. The peak temperature $\left(T_{P}\right)$ calculated from DTG plots of control cotton fabric is $\sim 322{ }^{\circ} \mathrm{C}$ and for CF 12APP-Si and CF 15APP are $\sim 339{ }^{\circ} \mathrm{C}$, it is possibly due to acid catalyses reactions in control CF. The mass loss $\left(M_{P}\right)$ relating to $T_{P}$ for intumescent formulation coated is lesser (range $36-40 \%$ ) as compared to CF (45\%).

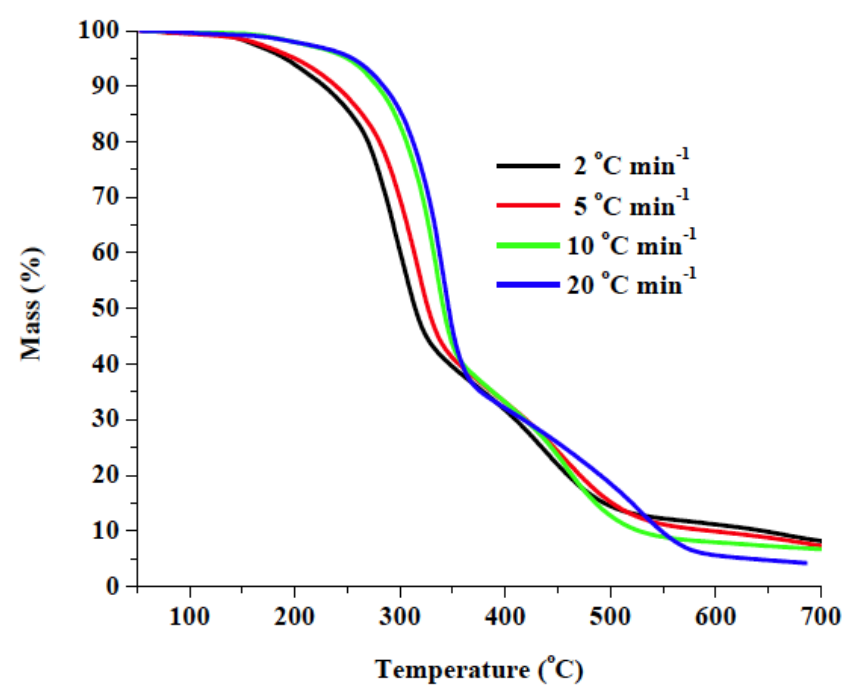

Figure 6: TG curves for CF 12APP at different heating rates of $2,5,10$ and $20{ }^{\circ} \mathrm{C} \mathrm{min}{ }^{-1}$ in air.

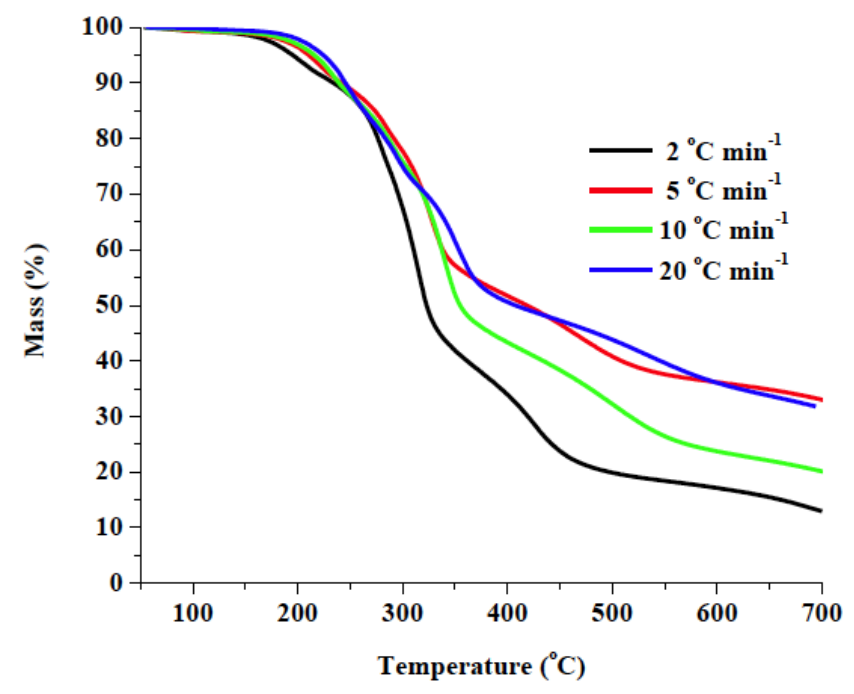

Figure 7: TG curves for CF 12APP-Fe at different heating rates of $2,5,10$ and $20{ }^{\circ} \mathrm{C} \min ^{-1}$ in air.

From the above observed values of TG and DTG investigation, it may be concluded that metal or $\mathrm{Si}$ insertion with intumescent formulation coated cotton fabric are thermally more stable than pure cotton fabric.

The onset temperature $T_{0}$, shift temperature $T_{S}$ from TG curves and peak temperature $T_{P}$, from DTG curves at which maximum mass loss was observed, 


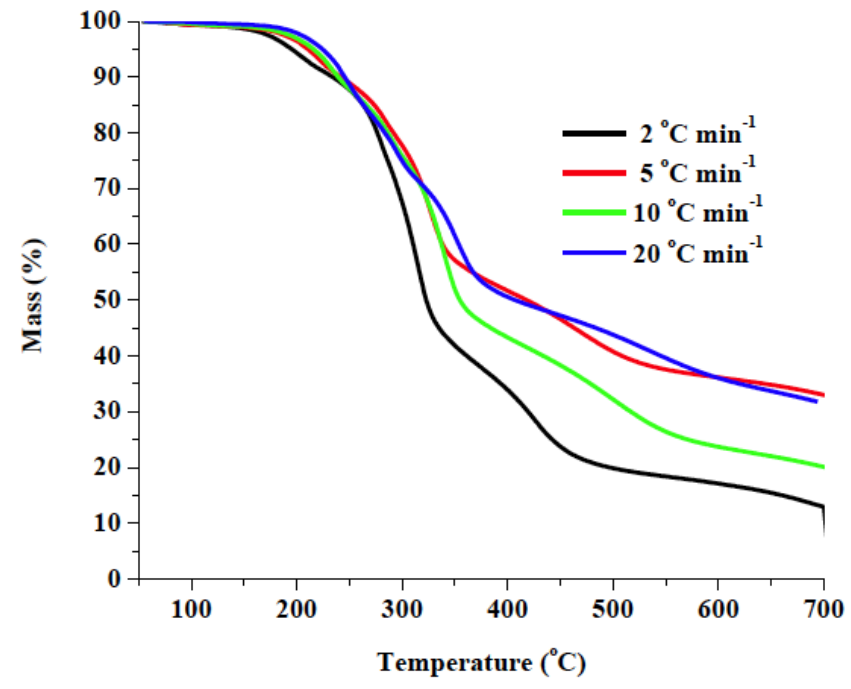

Figure 8: TG curves for CF 12APP-Si at different heating rates of $2,5,10$ and $20^{\circ} \mathrm{C} \mathrm{min}-1$ in air.

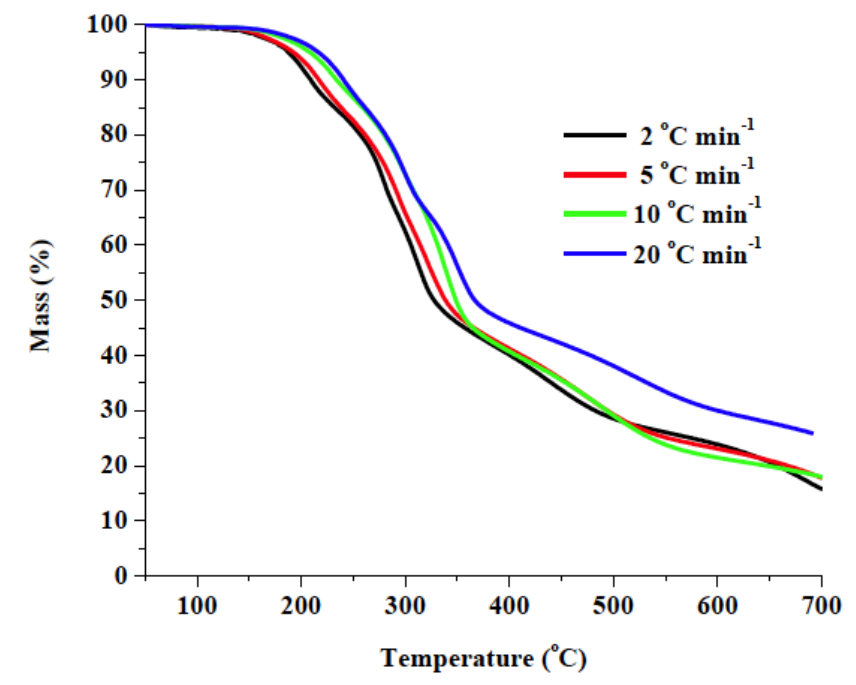

Figure 9: TG curves for CF 15APP at different heating rates of $2,5,10$ and $20^{\circ} \mathrm{C} \mathrm{min}{ }^{-1}$ in air.

were calculated for all samples from different heating rate. The temperature parameters $T_{O}, T_{S}, T_{P}$ and corresponding mass loss percentage parameters $\mathrm{ML}_{\mathrm{O}}$, $M L_{s}$ and $M L_{p}$, respectively were calculated by using Pyris manager software. The two parameters like maximum mass loss rate (MMLR), from DTG curves of all fabrics at heating rate of $10{ }^{\circ} \mathrm{C} \mathrm{min}{ }^{-1}$ Figure $10 \mathrm{~b}$, and char yield determined from TG curves are used to estimate flame retardancy quality of sample [27-29]. Greater value of char yield and lesser value of MMLR point toward the improvement in the flame retardancy of sample. MMLR was calculated from peak temperature of DTG curve and char yield was noted from TG curves at $650{ }^{\circ} \mathrm{C}$. The char yield and MMLR is presented in Table 2. The MMLR value for pure CF is $23.4 \% \cdot \mathrm{min}^{-1}$ and for intumescent coated samples it decreases to $11-18 \% \mathrm{~min}^{-1}$ that further decreases to 8 $9 \% / \mathrm{min}$ for inclusion of metal ion or Si into CF-APP sample. Char yield for CF is $2 \%$ and increases to $4-19$ $\%$ for CF-APP-Fe/Si samples by incorporation of metal ion or $\mathrm{Si}$ into the intumescent formulation. The decrease in MMLR value and increase in char yield of metal-intumescent coated fabrics compared to pure fabric represent that depolymerisation reaction in coated samples occur at slower rate.

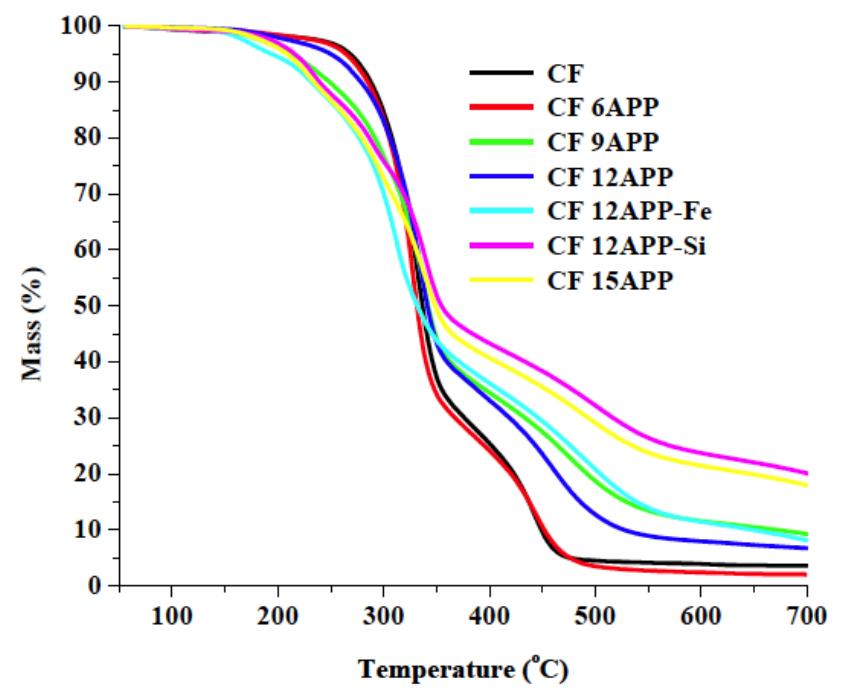

a

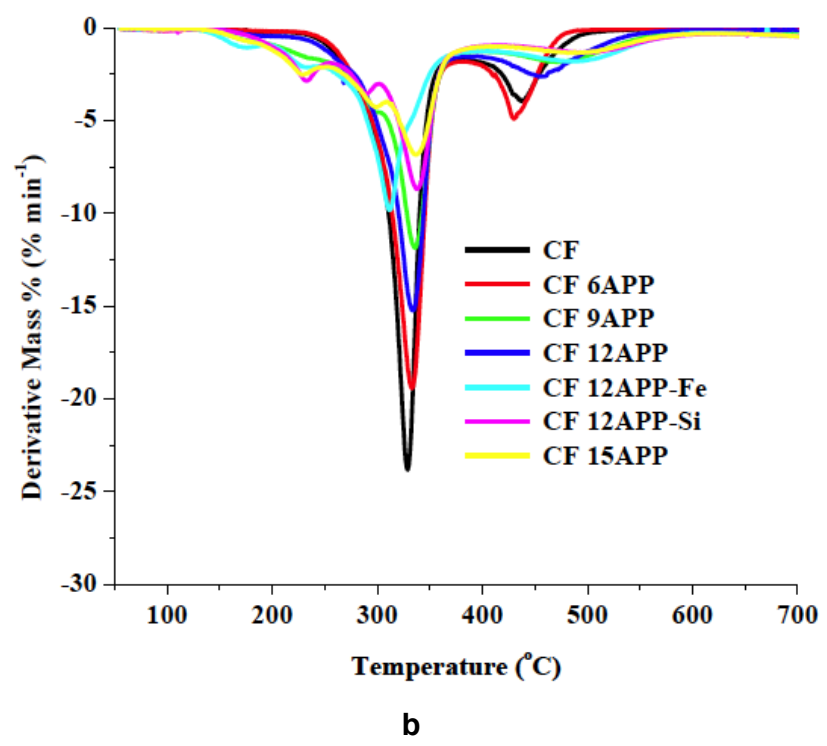

Figure 10: a: TG curves of all samples at heating rate of 10 ${ }^{\circ} \mathrm{C} \min ^{-1}$ in air.

b: DTG curves of all samples at heating rate of $10{ }^{\circ} \mathrm{C} \mathrm{min}^{-1}$ in air.

This is perhaps due to formation of charred protective layer and insertion of metal ions in the matrix of macromolecules that catalysis cross linking which suppress the formation of volatile products formed during heating of polymers in air. This study concluded 
Table 2: Thermal Decomposition Parameters of CF and Intumescent Coated CF

\begin{tabular}{|c|c|c|c|c|c|c|c|c|c|}
\hline Samples & $\begin{array}{l}\mathrm{T}_{\circ} \\
\left({ }^{\circ} \mathrm{C}\right)\end{array}$ & $\begin{array}{l}M L_{\circ} \\
(\%)\end{array}$ & $\begin{array}{c}\mathrm{T}_{\mathrm{s}} \\
\left({ }^{\circ} \mathrm{C}\right)\end{array}$ & $\begin{array}{c}M L_{s} \\
(\%)\end{array}$ & $\begin{array}{c}\mathrm{T}_{\mathrm{P}} \\
\left({ }^{\circ} \mathrm{C}\right)\end{array}$ & $\begin{array}{l}M L_{P} \\
(\%)\end{array}$ & $\begin{array}{c}\text { Temperature } \\
\text { Range } \\
\left({ }^{\circ} \mathrm{C}\right)\end{array}$ & $\begin{array}{c}\text { MMLR } \\
\left(\% \min ^{-1}\right)\end{array}$ & $\begin{array}{c}\text { Char yield at } \\
650^{\circ} \mathrm{C} \\
(\%)\end{array}$ \\
\hline $\mathrm{CF}$ & 281.37 & 5.2 & 349.2 & 64.5 & 322.98 & 45.2 & $245-367$ & 23.4 & 2.1 \\
\hline CF 6APP & 275.24 & 4.2 & 347.46 & 66.3 & 328.79 & 40.1 & $243-369$ & 18.8 & 3.6 \\
\hline CF 9APP & 278.26 & 14.6 & 351.36 & 58.6 & 335.98 & 38.5 & $270-360$ & 15.8 & 7.3 \\
\hline CF 12APP & 291.06 & 9.2 & 348.64 & 58.5 & 333.77 & 36.0 & $270-362$ & 12.3 & 8.5 \\
\hline CF 12APP-Fe & 290.49 & 23 & 330.1 & 52.1 & 311.70 & 34.2 & $254-350$ & 9.0 & 9.9 \\
\hline CF 12APP-Si & 318.13 & 28.3 & 353.4 & 50.8 & 338.00 & 37.5 & $300-360$ & 8.3 & 22.0 \\
\hline CF 15APP & 276.19 & 18.8 & 354.48 & 53.4 & 339.26 & 36.7 & $309-362$ & 11.8 & 19.9 \\
\hline
\end{tabular}

that all intumescent coated fabrics show good flame retardancy and CF 12APP-Si the best.

\subsection{Degradation Activation Energy}

The degradation activation energy of samples have been calculated using model free Friedman (Table 3), O-F-W and modified Coats-Redfern methods. Friedman method depends upon multiple heating rates; there is plot of $\ln (\beta(d \alpha / d T))$ verses $1 / T$ at particular value of degree of conversion. The slop of lines obtained were $-E / R$. In the Friedman plot of CF 9APP (Figure 11a), all the lines are having regression of 0.99 for different degree of conversions (0.05-0.65). The Friedman plots (Figure 11b) of activation energy versus degree of conversions expresses the similarity in all curves, that the value of activation energy is small for small conversions $(0.03-0.09)$ in $1^{\text {st }}$ stage of thermal degradation, and also small activation energy values in

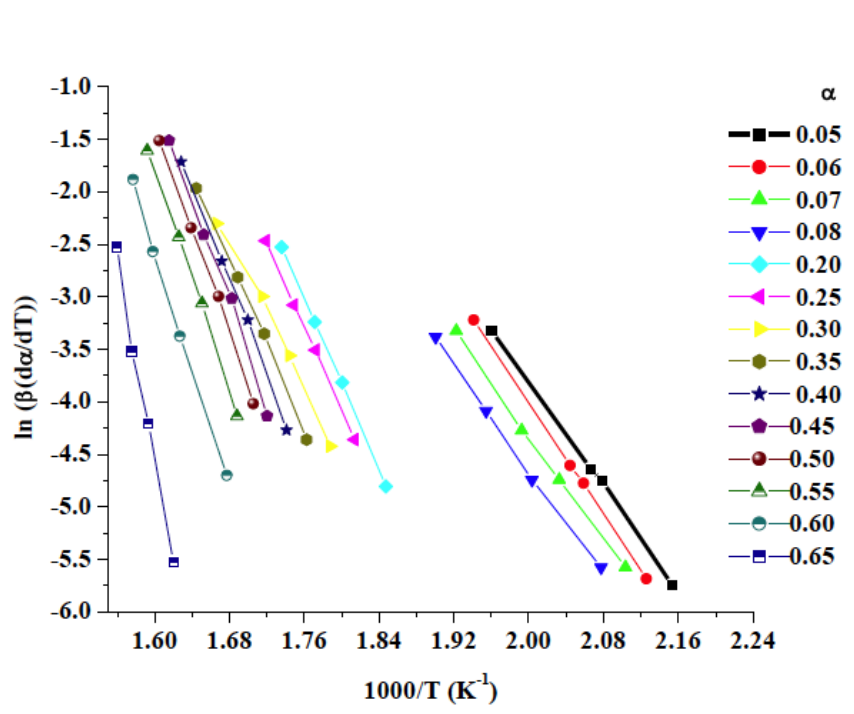

a $3^{\text {rd }}$ stage of thermal degradation $(\alpha=0.70-0.90)$. Where as in $2^{\text {nd }}$ stage of thermal degradation the activation energy is very large $(\alpha=0.20-0.65)$.

In the $1^{\text {st }}$ stage of degradation of fabric or treated fabric, removal of simple molecules is taking place like water, ammonia etc. In this stage there is no significant role of phosphates. In the $2^{\text {nd }}$ stage of degradation formation of volatile products occur which further propagate fire and hence large mass loss takes place in $\mathrm{CF}$, means activation energy for this stage is lower in control fabric (Table 3). But in intumescent coated fabrics the formation of volatile products slightly reduced due to protective layer of phosphates shielded under lying substrate.

In the $3^{\text {rd }}$ stage of degradation the volatile products (levoglucosan) produced in $2^{\text {nd }}$ stage get oxidized and formed char. The activation energy increases

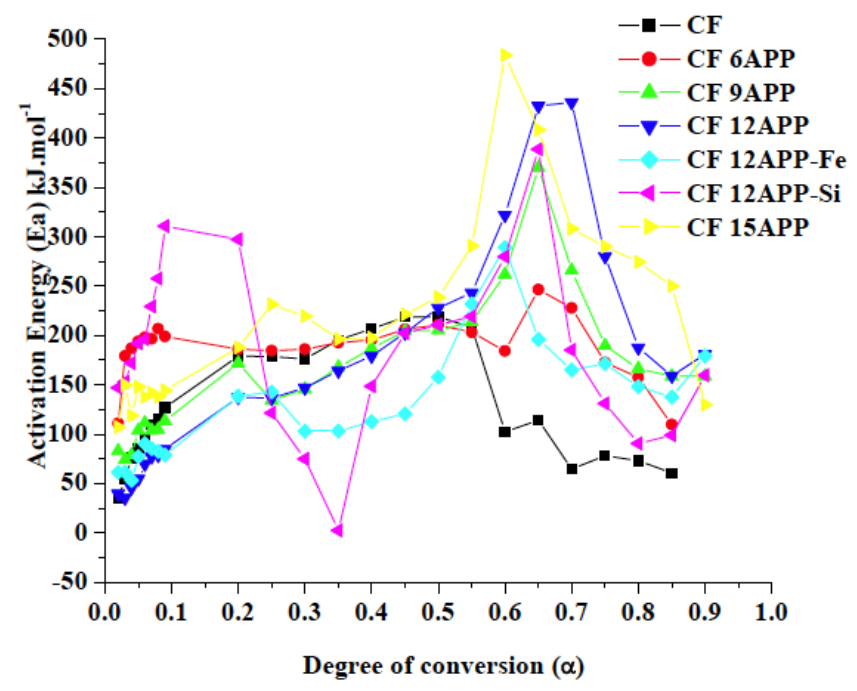

b

Figure 11: a: Friedman plot of CF 9APP at various degree of conversions ( $\alpha$ ).

b: Friedman plot of activation energies for CF and its derivatives at various degrees of conversions ( $\alpha$ ). 
Table 3: Activation Energy ( $\mathrm{kJ} \mathrm{mol}^{-1}$ ) Calculated by Friedman Method for All Fabrics at Varying Degree of Conversion (a)

\begin{tabular}{|c|c|c|c|c|c|c|c|}
\hline$\alpha$ & $\mathrm{CF}$ & 6 APP & 9 APP & 12 APP & 12 APP-Fe & 12 APP-Si & 15 APP \\
\hline 0.02 & 35.75 & 111.07 & 83.14 & 39.90 & 61.52 & 147.15 & 107.08 \\
\hline 0.03 & 54.04 & 179.33 & 73.99 & 35.75 & 61.52 & 152.97 & 149.90 \\
\hline 0.04 & 75.74 & 186.98 & 78.98 & 45.72 & 53.20 & 172.09 & 118.72 \\
\hline 0.05 & 86.21 & 193.88 & 103.92 & 54.87 & 77.32 & 192.05 & 147.98 \\
\hline 0.06 & 96.02 & 198.20 & 111.40 & 69.83 & 90.62 & 196.21 & 137.59 \\
\hline 0.07 & 109.66 & 196.54 & 103.92 & 77.32 & 85.38 & 229.46 & 141.87 \\
\hline 0.08 & 115.23 & 206.76 & 104.83 & 78.98 & 82.89 & 257.73 & 137.76 \\
\hline 0.09 & 126.78 & 198.87 & 113.40 & 84.80 & 78.98 & 310.61 & 144.33 \\
\hline 0.20 & 179.24 & 185.98 & 171.85 & 137.5 & 138.67 & 297.30 & 187.81 \\
\hline 0.25 & 178.58 & 184.48 & 134.27 & 136.4 & 142.83 & 121.46 & 231.46 \\
\hline 0.30 & 176.09 & 186.06 & 145.66 & 146.98 & 103.25 & 74.826 & 219.40 \\
\hline 0.35 & 195.46 & 192.71 & 167.77 & 164.28 & 103.17 & 82.49 & 196.29 \\
\hline 0.40 & 206.93 & 195.37 & 187.06 & 179.24 & 112.90 & 148.48 & 197.37 \\
\hline 0.45 & 218.40 & 206.10 & 204.52 & 202.69 & 120.55 & 202.36 & 221.40 \\
\hline 0.50 & 218.99 & 210.67 & 205.35 & 227.96 & 157.96 & 210.75 & 238.61 \\
\hline 0.55 & 208.34 & 203.19 & 213.66 & 243.10 & 231.96 & 219.07 & 290.49 \\
\hline 0.60 & 102.34 & 184.15 & 261.89 & 322.00 & 289.24 & 279.84 & 483.70 \\
\hline 0.65 & 114.31 & 246.59 & 369.97 & 432.32 & 195.87 & 388.43 & 408.30 \\
\hline 0.70 & 64.84 & 227.72 & 266.04 & 435.90 & 165.03 & 185.06 & 308.01 \\
\hline 0.75 & 78.15 & 172.59 & 189.55 & 280.18 & 171.26 & 131.02 & 290.12 \\
\hline 0.80 & 73.16 & 157.55 & 166.28 & 187.48 & 148.15 & 90.622 & 274.36 \\
\hline 0.85 & 60.69 & 109.82 & 158.79 & 159.04 & 137.67 & 98.936 & 250.00 \\
\hline 0.90 & 45.72 & -- & 158.79 & 180.99 & 179.24 & 159.54 & 130.00 \\
\hline
\end{tabular}

remarkably in $3^{\text {rd }}$ stage by polyphosphate layer cover the underlying substrate, which retards the contact of volatile products with fire. Therefore the activation energy value is large in intumescent coated fabric compared to control. With the insertion of metal ion $(F e)$ leads to enhances the activation energy for $3^{\text {nd }}$ stage of degradation [10]. In final stage Ea value is greatly increased for 15 APP $(483 \mathrm{~kJ} / \mathrm{mol})$ then 12 APP-Si (289) followed by 12 APP-Fe (279) and least value for CF $(102 \mathrm{~kJ} / \mathrm{mol})$ at 0.60 degree of conversion (Table 3). It may be concluded that the 15 APP is most thermally stable among all treated fabrics.

Ozawa-Flynn-Wall method is based on temperature of thermal degradation reaction by power law kinetics. This method used the approximation of Doyle to evaluate the integrated form of rate equation. According to this method a plot of log $(\beta)$ verses $1 / T$ at constant degree of conversion and slop of line is given by $-0.4567 \mathrm{E} / \mathrm{R}$. The plot of O-F-W for all samples were absolute linear, here plot of CF (Figure 12a) is given for different degree of conversions (0.04-0.85), it also shows the regression is more than 0.99 in most of the cases. The results of O-F-W in respect of activation energies in different stages of thermal degradation is quite different as compare to other kinetic methods for all modified CF samples (Figure 12b). The last method which we have applied on thermal degradation kinetics of above prepared samples is Coats-Redfern (modified). The plot of $\ln \left(\beta / T^{2}\right)$ verses $1 / T$, gives slop of line $-E / R$. According to the plots of Coats-Redfern for CF 12APP shown in (Figure 13a), the lines are absolute linear for various degree of conversions for $2^{\text {nd }}$ stage of thermal degradation (0.20-0.75). Activation energies during thermal degradation of above prepared samples were calculated at various degrees of conversions and represented in (Figure 13b). The isoconversional plots of Ea show the general trend of activation energy. The linear fitted plots of samples are 


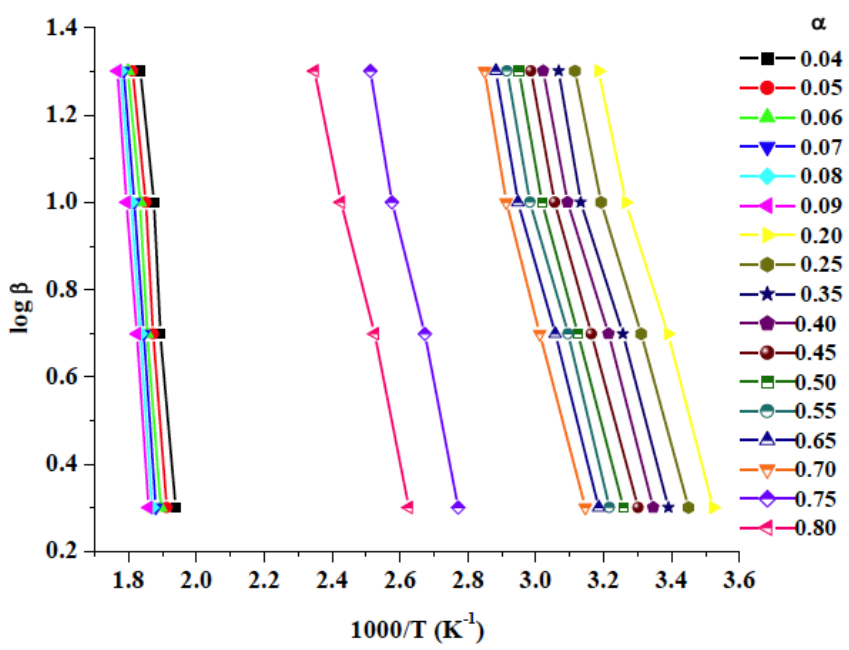

a

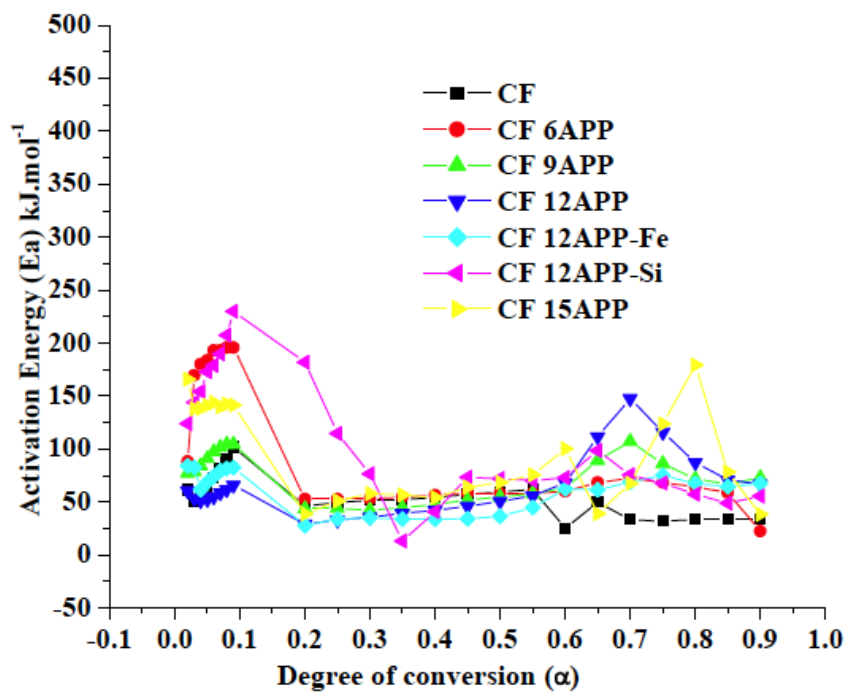

b

Figure 12: a: O-F-W plot of CF at various degrees of conversions $(\alpha)$.

b: O-F-W plot for activation energies of Cotton Fabric and its derivatives at various degrees of conversions ( $\alpha$ ).

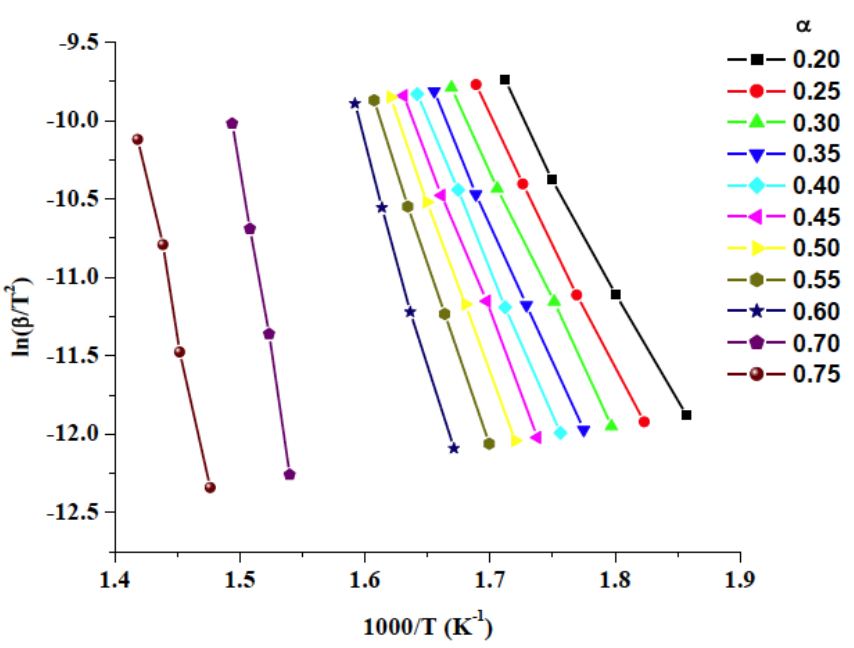

a

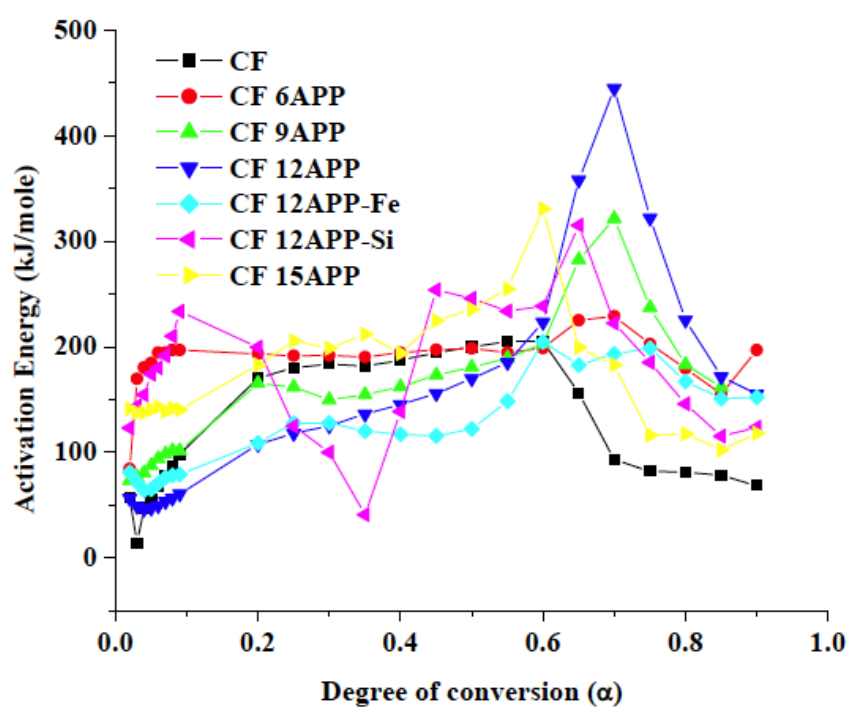

b

Figure 13: a: Coats-Redfern plots of CF 12APP at various degrees of conversions $(\alpha)$.

b: Coats-Redfern plots for activation energies of CF and its derivatives at various degrees of conversions ( $\alpha$ ).

parallel indicating the possibility of single order of degradation mechanism [30-32].

Activation energy of CF 9APP is compared by three kinetic methods, (Figure 14) shows that the curves are quite congruent for Friedman and Coats-Redfern method for broad range of degree of conversion (0.020.85 ) but the curve of O-F-W method for CF 9APP is congruent to above methods only in small degree of conversions (0.02-0.09), for higher fractions the curves are similar but the magnitude of activation energy is quite different i.e. Ea values for 9 APP were 261, 195 and $60 \mathrm{~kJ} / \mathrm{mol}$ at $\alpha=0.60$ calculated by applying Friedman, Coats-Redfern and O-F-W method respectively. It may be concluded that O-F-W method is similar to non isothermal kinetic methods qualitatively while not suitable for kinetic study of thermal degradation of polymers quantitatively.

\section{CONCLUSIONS}

The Intumescent coating on cotton fabric in various ratios increases the flame ratardancy of substrate fabric due to inclusion of phosphate which makes 


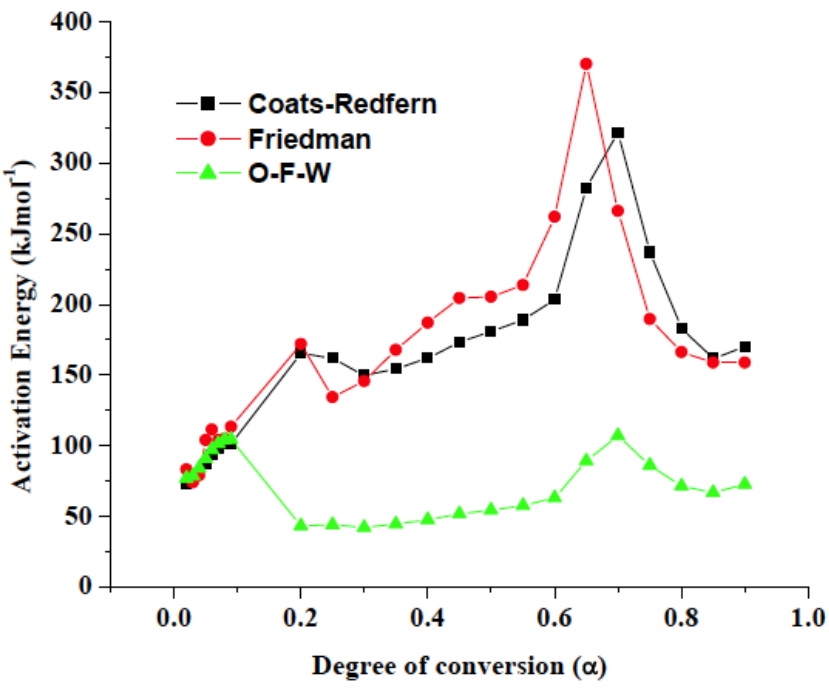

Figure 14: Plots for activation energies of CF 9APP by three kinetic methods at various degrees of conversions $(\alpha)$.

shield on fabric to disconnect the approach of fire to fabric at lower temperatures. The maximum flame ratardancy of CF 12APP-Si among all cotton derivatives is suggested as the flame retardancy directly proportional to char yield $\left(22 \%\right.$ at $\left.650{ }^{\circ} \mathrm{C}\right)$ that is highest and inversely proportional to MMLR value $\left(8.3 \% \mathrm{~min}^{-1}\right)$, that is least among all samples.

Pure cotton fabric shows two stages of thermal degradation while all intumescent coated cotton fabrics show three stages of thermal degradation. Activation energy of thermal degradation of all samples were calculated at four heating rates were calculated by model free kinetic methods at series of degree of conversions. The pattern of activation energy curve for pure cotton fabric shows small value at lower degree of conversion (0.03-0.09) and for very higher degree of conversions $(0.55>)$ but higher values in intermediate conversions (0.20-0.50) which is main stage for thermal degradation. Similar results are shown by intumescent coated cotton fabrics for $1^{\text {st }}$ and $2^{\text {nd }}$ stage, but the magnitude of activation energy values is quite different. In the $3^{\text {rd }}$ stage of thermal degradation for treated fabrics is higher as compared to virgin because the polyphosphate layer of intumescent shielded the underlying substrate which cut the contact of fire with levoglucosan formed in previous stage of degradation. The activation energy for intumescent coated samples than CF at onset temperature is small, but Ea value for coated samples increases with increasing $\alpha$ as compared to CF.

Activation energy for thermal degradation of CF 9APP were similar for Friedman and Coats-Redfern but having lower values in Ozawa-Flynn-Wall plot, corresponding to same degree of conversions.

Crease recovery angle of treated fabrics was decreased up to $83^{\circ}$ for CF 12APP-Fe which was $95^{\circ}$ for substrate fabric. Tensile strength of CF 12APP-Si was $42 \mathrm{~N} . \mathrm{mm}^{-2}$ elongations at break of $18 \mathrm{~mm}$, nearly equal to pure cotton fabric.

\section{REFERENCES}

[1] Shafizadeh F, Lai YZ, Mcintyre CR. Thermal degradation of 6-chlorocellulose and cellulose-zinc chloride mixture. J Appl Polym Sci 1978; 22: 1183-93. http://dx.doi.org/10.1002/app.1978.070220503

[2] Bhagwan J, Arora S, Lal K. Thermal and spectroscopic studies on cellulose and its phosphorylated products in air. $J$ Polym Mater 1990; 7: 231-7.

[3] Arora S, Bhatnagar HL. Thermal and spectral studies of cellulose and cellulose aryl phosphates. J Polym Mater 1992; 9: 35-42.

[4] Singh R, Arora S, Lal K. Thermal characteristics of cellulose 2-chlorophenylthiophosphate and its metal complexes. J Polym Mater 1995; 12: 263-71.

[5] Betts KS. New thinking on flame retardants. Enviorn Health Perspect 2008; 116: A210-3. http://dx.doi.org/10.1289/ehp.116-a210

[6] Huang X, Zhang WD. Preparation of cellulose sulphate and evaluation of its properties. J of Fiber Bioengineering and Informatics 2010; 3: 32-9.

http://dx.doi.org/10.3993//fbi06201006

[7] Arju SN. Use of transition metal ions to enhance flame retardancy of ammonium polyphosphate treated back coated cotton fabrics. International Journal of Engineering \& Technology IJET-IJENS 2010; 10: 20-3.

[8] Hebeish A, Waley A, El-Kashouti MA. Durable flame resistance via reaction of cotton cellulose bearing aromatic amino group with tetrakis(hydroxymethyl)phosphonium chloride. J Appl Polym Sci 1979; 23: 1803-10. http://dx.doi.org/10.1002/app.1979.070230620

[9] Reshetnikov I, Antonov A, Rudakova T, Aleksjuk G, Khalturinskij N. Some aspects of intumescent fire retardant systems. Polym Degrad Stab 1996; 54: 137-41. http://dx.doi.org/10.1016/S0141-3910(97)81483-8

[10] Dahiya JB, Kumar K. Flame retardant study of cotton coated with intumescents: kinetics and effected metal ions. J Sci Ind Res 2009; 68: 548-54

[11] Langille K, Ngayen D, Veinot DE. Inorganic intumescent coating for improved fire protection of GRP. Fire Tech 1999; 35: $99-110$

http://dx.doi.org/10.1023/A:1015459720909

[12] Horrocks AR. Development in flame retardants for heat and fire resistant textiles-the role of char formation and intumescence. Polym Degrad Stab 1996; 54: 143-54. http://dx.doi.org/10.1016/S0141-3910(96)00038-9

[13] Brown ME, Maciejewski M, Vyazovkin S, et al. Computational aspects of kinetic analysis Part A: The ICTAC kinetic projectdata, methods and results. Thermochim Acta 2000; 355: 125-43.

http://dx.doi.org/10.1016/S0040-6031(00)00443-3

[14] Friedman HL. Kinetics of thermal degradation of char-forming plastics from thermogravimetry. Application to phenolic plastic. J Polym Sci Part C-Polym Symp 1964; 6: 183-95. http://dx.doi.org/10.1002/polc.5070060121 
[15] Brown AL, Dayton DC, Daily JW. A study of cellulose pyrolysis chemistry and global kinetics at high heating rates. Energ Fuel 2001; 15: 1286-94. http://dx.doi.org/10.1021/ef010084c

[16] Flynn JH, Wall LA. General treatment of thermogravimetry of polymers. J Res Nat Bur Stand-A. Phy Chem 1966; 70A: 487-523.

[17] Cabrales L, Abidi N. On the thermal degradation of cellulose in cotton fibres. J Therm Anal Calorim 2010; 102: 485-91. http://dx.doi.org/10.1007/s10973-010-0911-9

[18] Ming L. Crease resistant finishing of cotton fabric with a complex of fibroin and citric acid. Fibres Text East Eur 2010; 18: 86-8.

[19] Can Y, Akaydin M. Effect of Wrinkle Resistant Finish on Cotton Fabric Properties. Indian J Fibre Text 2009; 34: 1836.

[20] Ramachandran T, Gobi N, Rajendran V, Lakshmikantha CB. Optimization of process parameters for crease resistant finishing of cotton fabric using citric acid. Indian J Fibre Text 2009; 34: 359-67.

[21] Wei $W$, Yang $C Q$. Predicting the performance of durable press finished cotton fabric with infrared spectroscopy. Text Res J 1999; 34: 145-51.

[22] Yang CQ. Crosslinking: a route to improve cotton, The University of Georgia AATCC, Copyright (c) 2013 AATCC. 2013; 1-44.

[23] Kang In-Sook, Yang CQ, Wei W, Gary CL. Mechanical strength of durable press finished cotton fabrics: part I: effects of acid degradation and crosslinking of cellulose by polycarboxylic acids. Text Res J 1998; 68: 865-70. http://dx.doi.org/10.1177/004051759806801112

[24] Prakash Y, Mahadevaiah D, Somashekarappa H, Demappa $\mathrm{T}$, Somashekar R. Microstructural parameters of HPMC/PVP polymer blends using wide angle X-ray technique. J Res Updates Polym Sci 2012; 1: 24-31.

http://dx.doi.org/10.6000/1929-5995.2012.01.01.4

[25] Waichiro T. On the lowering of the tensile strength of cotton fiber caused by the intermolecular crosslinking. Bull Inst Chem Res Kyoto Univ 1971; 49: 69-79.

[26] Gaur S, Reed TB. Prediction of cellulose decomposition rates from thermogravimetric data. Biomass Bioenerg 1994; 7: 617.

http://dx.doi.org/10.1016/0961-9534(94)00047-W

[27] Arora S, Kumar M, Kumar M. Catalytic effect of bases in impregnation of guanidine nitrate on poplar (populus) wood: flammability and multiple heating rate kinetic study. J Therm Anal Calorim 2012; 107: 1277-86. http://dx.doi.org/10.1007/s10973-011-1779-z

[28] Kumar M, Kumar M, Arora S. Thermal degradation and flammability studies of wood coated with fly ash intumescent composites. J Indian Acad Wood Sci 2013; 10: 125-33. http://dx.doi.org/10.1007/s13196-013-0105-8

[29] Liodakis S, Antonopoulos I, Kakardakis T. Evaluating the use of minerals as forest fire retardants. Fire Safe J 2010; 45: 98105.

http://dx.doi.org/10.1016/j.firesaf.2009.11.002

[30] Kumar S, Kumar M, Lal S, Kumar S, Arora S. Model free heating rate degradation kinetic studies of modified celluloses. Chem Sci Trans 2015; 4: 181-93.

[31] Arora S, Lal S, Kumar S, Kumar M, Kumar M. Comparative degradation kinetic studies of three biopolymers: Chitin, chitosan and cellulose. Arch Appl Sci Res 2011; 3: 188-201.

[32] Shafizadeh F, Bradbury AGW. Thermal degradation of cellulose in air and nitrogen at low temperatures. J Appl Polym Sci 1979; 23: 1431-42. http://dx.doi.org/10.1002/app.1979.070230513 